\title{
Bridging the gap: An exploration of the use and impact of positive action in the UK
}

\author{
Chantal M Davies ${ }^{1}$ \\ (Forum for Research into Equality and Diversity) University of Chester, UK \\ Muriel Robison
}

(Law School) University of Chester, UK

\begin{abstract}
Despite laws in Britain permitting limited positive action initiatives to combat disadvantage faced by minority groups in employment since the mid-1970s, the subject has notoriously been a neglected and highly controversial area in the UK. Notwithstanding the potential provided by sections 158 and 159 of the Equality Act 2010, it still appears that organisations prefer to steer clear of this opportunity to address disadvantage suffered by protected groups. Whilst there is a body of work considering the theoretical importance of positive action in the UK, there is a lack of empirical exploration of the practical implications of these provisions. This paper will provide a brief overview of the theoretical context and current positive action legislative provisions within the UK. In light of this context, the early findings of a small-scale qualitative study carried out by the authors will be discussed looking at the experiences of a purposive sample of public and private employers in relation to the positive action provisions of the Equality Act 2010. Early research findings suggest that whilst there was a clear willingness and openness by employers to use of outreach measures in order to redress disadvantage, there was evident wariness regarding a move towards preferential treatment as expounded by section 159. Whilst respondents appeared to appreciate the business case for and utility of the positive action measures under section 158, there was far less enthusiasm for more direct preferential treatment, with many respondents raising serious concerns regarding this. These concerns often reflected a highly sensitive risk-based approach towards any action that could expose their organisation to the possibility of "reverse discrimination".
\end{abstract}

1 Corresponding author:

Forum for Research into Equality and Diversity, Law School, University of Chester, Parkgate Road, Chester, CH1 4BJ, UK.

Email: chantal.davies@chester.ac.uk 


\section{Keywords}

Positive action; employment; equality; recruitment.

\section{Introduction}

Since the mid-1970s laws have existed in the UK permitting limited forms of positive action in employment in order to redress disadvantage faced by minority groups. Since the inception of "affirmative action" in the United States in the 1960s, the related term "positive action" has been increasingly used in a social, legal and policy context in the UK over the last 40 years. Positive action involves the 'use of special measures to assist members of disadvantaged groups in overcoming the obstacles and discrimination they face in contemporary society' (O'Cinneide, 2009: 279). These "special measures" are intended to ensure "equality of opportunity" as opposed to "equality of outcome" (O'Cinneide, 2009) $)^{2}$. Any attempted development in relation to positive action in the UK has arguably been contentious due to the potential for "reverse discrimination" (Fredman, 2011) ${ }^{3}$. More recently the existing positive action provisions for the individual protected characteristics were largely transferred into the Equality Act 2010 (section 158 Equality Act 2010). This was however subject to a broader approach in the new section 158 arguably moving from the previous "equality of opportunity" approach towards an "equality of results" model (Burrows \& Robison, 2006) (see below for further discussion). In 2011, further legislative development of positive action unfurled with the implementation of section 159 of the Equality Act 2010. Thus, positive action in the UK progressed into fresh terrain permitting organisations to utilise a 'tie-break' provision in the employment

2 These terms are not used by the authors as accepted conceptual terms. It is recognized that there are those such as Khaitan $(2015: 83,216)$ who would argue that positive action measures are more appropriately divided on the basis of the tools employed and that these tools may be distributive (e.g. tie-break rules, job quotas) or facilitative (eg reporting requirements).

3 It should be noted that there is emerging debate around the importance of moving away from labelling positive action measures as "reverse discrimination" (Khaitan, 2015). 
sphere in relation to recruitment and promotion. In many ways this could be seen as a form of preferential treatment (in line with McCrudden's, 1986 categorisation of positive action). Whilst sections 158 and 159 are permissive rather than mandatory, arguably the Public Sector Equality Duty under section 149 of the Equality Act 2010 places an onus on the public sector to have due regard to the need to redress disadvantage via the positive action provisions.

The challenge of redressing disadvantage suffered by protected groups via the permissive provisions of section 159 (in particular) appears to have largely been ignored by employers. This is supported by the lack of case law demonstrating use by employers as well as a dearth in good practice examples demonstrating use of section 159. Indeed the research that forms the basis of this paper further reinforces this. Exceptionally, the Judicial Appointments Commission (JAC) announced its intention to use the 'equal merit provision' in recruitment exercises from 1 July 2014 in order to promote diversity within the judiciary (Judicial Appointments Commission, 2014; Malleson, 2009). Similarly, there are indications that trade unions in male dominated sectors are seeking to promote employer engagement with positive action initiatives (see for example work carried out for ASLEF by Robison, 2012). In spite of a few notable anecdotes and reports pointing to limited engagement by employers with positive action and a developing theoretical dialogue (see inter alia Barmes, 2011; Burrows \& Robison, 2006; Johns et al, 2014; McCrudden 1986; Noon, 2010), there is a lack of empirical exploration in this area. As we pass the fifth anniversary of the Equality Act 2010, it is contended that socio-legal qualitative study to determine attitudes of employers towards the legislative positive action provisions is both opportune and essential.

This paper will briefly provide an overview of the theoretical and legal context of the current positive action provisions contained within the Equality Act 2010 before discussing the early findings of a limited qualitative scoping study into the attitudes and experiences towards the positive action provisions of a small purposive sample of employers in England, Scotland and Wales. It is not the purpose of this paper to provide a detailed critique of the conceptual or legal framework other than from the perspective of the attitudes of those employers sampled. 


\section{Conceptualising positive action}

Whilst this paper will not seek to challenge the existing conceptual dialogue (see inter alia, O'Cinneide, 2009; Noon, 2011; Barmes, 2011) in this area, it may be useful to briefly explore the theoretical basis on which positive action rests. Whilst the term positive action involves the use of special measures to redress disadvantage in order to achieve equality of opportunity (O'Cinneide, 2009), the term "positive discrimination" more closely resembles the US concept of "affirmative action". Positive discrimination moves towards seeking to achieve "equality of outcome" by recognising the inherent disadvantage faced by those with a particular characteristic. In this way, the characteristic becomes a legitimate criterion for evaluating individuals in any formal decision making. In other words, positive discrimination could be said to be a means of redressing historic disadvantage via a process of what may be called reverse discrimination. Whilst some (such as Noon, 2010) have advocated the case for reconsidering positive discrimination as a viable policy intervention, EU law (as seen in cases such as Briheche v Ministre d l'Interior, de l'Education and de la Justice [2004] ECR I-8807 and Abrahamsson and Anderson v Fogelqvist [2000] ECR I-5539) and therefore domestic legislation have thus far refused to accept positive discrimination as a valid means of addressing historic disadvantage and underrepresentation.

As recognised by those such as O'Cinneide (2009), positive action measures do not take any standardised form and should necessarily be tailored to the particular situation. While legal regulation is necessary to ensure boundaries to positive action, equally those who may wish to use such measures may be dissuaded from doing so for fear of costly litigation by a disaffected majority bringing reverse discrimination claims. This clearly feeds into the reflexive regulation debate where the trick is 'for the legal system to construct a set of procedural stimuli that lead to the targeted subsystem adapting itself' (McCrudden, 2007) $)^{4}$.

4 Whilst the reflexive regulation debate in the context of equality (see inter alia Ayres and Braithwaite, 1992; Morgan and Yeung, 2007; McCrudden, 2007;

Hepple, 2011 etc) is both relevant and important in relation to the positive action agenda, it is beyond the scope of this paper. 
Attempts have been made over a number of years to conceptualise positive action measures across a typology of approach. In particular, McCrudden's (1986) five-step typology of positive action whilst controversial and viewed by some as outdated (see for example Khaitan, 2015; Barmes, 2009) is still useful in providing clarity where often there has been none. Some, such as Burrows and Robison (2006), have attempted to fit the European Union (EU) case law into this conceptual framework and, in so doing, have attempted to uncover a paradigm approach to the EU jurisprudence. McCrudden's typology briefly covers:

- Eradicating discrimination: identifying and replacing discriminatory practices;

- Purposefully inclusionary policies: facially neutral policies that seek to increase the proportion of members of the disadvantaged group;

- Outreach programmes: programmes designed to attract qualified candidates from the previously underrepresented or disadvantaged group;

- Preferential treatment: plans to reduce the underrepresentation or disadvantage by introducing what may be called 'reverse discrimination' in favour of members of the disadvantaged group;

- Redefining merit: an alteration to the qualifications necessary to do the job by including the protected characteristic as a relevant qualification in order to be able to do the job properly.

McCrudden's typology was not intended to conceptualise what was at that time legally permissible in relation to positive action. Rather, it was intended to be a 'rubric of what positive action might include' (McCrudden, 1986, 223). Whilst categories $1-3$ may safely fall within a definition of 'positive action', it may be that 4-5 more properly come under the more controversial category of 'positive discrimination' (Barmes, 2009). Previous law in the UK was (with perhaps the exception of disability and the explicit preferential provisions in the Sex Discrimination (Election Candidates) Act 2002) comfortably covered by the less controversial categories within McCrudden's typology. Arguably, the ambit of EU 
law and indeed the implementation of section 159 of the Equality Act 2010 has shifted the conceptual basis of positive action into the realms of "preferential treatment' in permitting employers to use a protected characteristic as a deciding factor in relation to recruit and promotion, albeit that this is subject to the important qualifications of proportionality and equivalency of qualification. Further, there are those such as Johns et al (2012) who argue that the tie-break provisions introduced by section 159 are not an aspect of positive action or even of 'positive discrimination'. They argue that the redefinition of merit so as to include a protected characteristic has radically redefined the tradition of equal opportunities (Johns et al, 2012,110). In this article, however, we categorise the section 159 provisions as "positive action", not least because that is how it is categorised in the Equality Act.

\section{The European context}

The previous domestic positive action provisions contained within the Sex Discrimination Act 1975 and the Race Relations Act 1976 permitting a limited range of positive action measures were increasingly out of step, both legally and conceptually, with the developing framework in EU law. Whilst there was no Community law definition of positive action, Article 141 (4) EC Treaty and Article 2(4) of Directive 76/207/EEC (Equal treatment of men and women) appeared to permit positive action measures in the employment field in relation to gender.

Whilst subsequent case law has not been able to provide an accepted standardised Community/Union approach towards positive action, it is possible to determine some boundaries in this area. At the nadir in relation to European approaches to positive action, the European Court of Justice (ECJ) in Kalanke v Bremen [1995] ECR I-3051 found that measures giving women priority in underrepresented sectors (where the women were equally qualified) went further than that permitted by the exception in Article 2(4). Only two years later the ECJ in Marschall $v$ Land Nordrhein Westfalen [1997] ECR I-6363 found that preferential treatment in a tie-break situation where female candidates for promotion were equally as qualified as male candidates in sectors where they are under-represented, did indeed fall within the scope of Article 2(4). The Court, however, made it clear that such a rule, in order to accord with Article 2(4), had 
to guarantee that candidates would be the subject of an objective assessment of all criteria specific to the individual candidates. Nevertheless, the Court refused to be drawn further than the Marschall scenario in Abrahamsson, when it found that measures which automatically gave preference in a recruitment process to candidates belonging to an under-represented gender where they were 'sufficiently qualified' (i.e. that the difference between the merits of the candidates is not so great as to result in breach of the requirement of objectivity) were not permitted under the Treaty or Directive. The court in Abrahamsson enforced the position that tie-break preference may be permitted, but only where candidates possess equivalent or substantially equivalent merits and subject to an overall test of proportionality. As such, the Court in Briheche found that a provision which removed age limit restrictions to public-sector employment for certain categories of women (but not to men in the same situation as these women) was not permitted under the Directive or Treaty as it was disproportionate. The boundaries of EU law would therefore preclude (on the basis of being disproportionate) any regime which seeks to exclude an individual from appointment or advancement simply because of a protected characteristic (Hepple, 2014: 158). Connolly (2011) suggests that the EU case law points to three requirements for positive action measures to be lawful, namely: underrepresentation; the woman must be equally qualified to the man; and there must be a 'savings clause' (as per the Kalanke/Marschall distinction) that an objective assessment of all criteria specific to the individual candidates should be considered. In more recent cases, such as Pedro Manuel Roca Alvarez v Sesa Start Espana ETT SA [2010] ECR I- 8661, the Court of Justice of the European Union (CJEU) have clarified that positive action measures which are 'underinclusive' (in the sense that they only assist a proportion of a disadvantaged group and in this case breastfeeding women) may not fall within the permitted boundaries of EU Law.

The earlier developing case law was largely reflected in Article 3 of the Recast Directive (2006/54/EC) amending the Equal Treatment Directive implementing the formula now set out in Article 157(4) of the Treaty on the Functioning of the European Union, which states: 
With a view to ensuring full equality in practice between men and women in working life, the principle of equal treatment shall not prevent any Member State from maintaining or adopting measures providing for specific advantages in order to make it easier for the underrepresented sex to pursue a vocational activity or to prevent or compensate for disadvantages in professional careers.

This was largely reflected in Article 5 of the Race Directive (although this instrument is not limited to employment matters) and Article 7(1) of the Framework Employment Directive (2000/78/EC) in relation to religion or belief, disability, age or sexual orientation. During the consultation to the Equality Act 2010, it was recommended by the Cambridge Review (Hepple et al., 2000) that legislation be brought in line with the broadened approach of EU law as interpreted by recent case law. As a result of this pressure internally and from EU law, the Equality Act 2010 was drafted in terms that took into account these case law developments in relation to recruitment and promotion via section 159.

It is clear that the EU perspective on positive action is still largely tentative and there is a broad range of positive action measures permitted and utilised. In 2005, the European Commission's Network of Legal Experts on the application of Community law on equal treatment between women and men carried out a broad-brush survey of positive action provisions across member states. Their findings were that positive action was clearly not seen as a priority by legislatures, social partners nor employers. Whilst every country had provision for some possibility to take positive action measures, there was very little evidence of impact or systematic analysis of effectiveness. The UK's response noted that 'there was little systematic research of how far [positive action] provisions, which in all cases are voluntary, have been taken up in practice by employers and others' (McCrudden, 2005: 62).

\section{The domestic legal context}

In drafting the Equality Act, it was recognised when it came to positive action that the laws to be replaced were more limited than was permitted by EU law. Thus the relevant provisions, in sections 158 and 159, as made clear in the Explanatory Notes to the Act (para 511 to 521), were drafted in a way that 
"extends what is possible to the extent permitted by European law" (see Burrows and Robison 2006). Although section 159 does permit an employer to take a protected characteristic into account when deciding who to promote or recruit, this is categorised, at domestic and European level, as positive action, since European law continues to be framed in terms of positive action and does not extend to permit positive discrimination. It is important to note that, unlike the antecedent legislation, section 158 extends the circumstances when positive action measures can be taken beyond the employment and training context, to include, for example, initiatives in relation to the exercise of public functions. The Explanatory Notes include the example of an NHS Primary Care Trust running a local awareness campaign for lesbians on the importance of cancer screening (para 517). However, in this article we focus on the positive action initiatives that can be undertaken by employers in particular, and other organisations covered by the Part 5 'work' provisions of the Equality Act, such as employment agencies, partnerships and those making appointments to public offices.

\section{Positive action: general provisions}

Section 158, headed "Positive Action: General", sets out the threshold conditions permitting positive action initiatives, and applies when an employer "reasonably thinks that -

a) Persons who share a protected characteristic suffer a disadvantage connected to that characteristic,

b) Persons who share a protected characteristic have needs that are different from the needs of persons who do not share it, or

c) Participation in an activity by persons who share a protected characteristic is disproportionately low. (section 158(1))."

This is an objective standard with a subjective element, since it is clear from the parliamentary debates on the Equality Bill (Hansard, 2010) that, where an employer identifies a need to tackle disadvantage or under-representation, their knowledge of their workforce profile or of comparable employers in the sector or of the picture nationally will be sufficient, without sophisticated statistical proof (EHRC, 2011 Code of Practice on Employment (paragraph 12.14)). 
Assuming that this (relatively low) threshold is met, then an employer will be entitled to take action which has the aim of overcoming or minimising the disadvantage, meeting differing needs, or enabling or encouraging participation of underrepresented groups (section 158(2)), so long as any initiatives are 'proportionate'. When considering whether an initiative is 'proportionate' account will need to be taken, of the seriousness of the disadvantage, the extent of the needs or under-representation, as well as whether there might be other ways in which the intended aims might be achieved (Explanatory Notes, para 512).

Examples of the types of action which employers can take would include encouraging particular groups to apply, or helping people with particular protected characteristics to perform to the best of their ability (see EHRC's Code of Practice on Employment (2011) (paragraphs 12.13 to 12.36)).

Positive action in recruitment and promotion

The general provisions described above will not apply in relation to recruitment and promotion. Instead, specific provisions are laid down in section 159 allowing for a protected characteristic to be taken into account at the point of recruitment or promotion, but only in certain prescribed circumstances. It is important to note, however, the very limited meaning given to "recruitment" set out in section 159(5), which refers very specifically to the offer of employment (or equivalent). Beyond that, the broader recruitment arrangements and initiatives deployed, for example to encourage an under-represented group to apply, will be governed by section 158.

An employer can take a candidate's protected characteristic into account if the following requirements are met:

1) the candidate is 'as qualified as' another candidate to be recruited or promoted (section 159(4)(a));

2) The employer 'reasonably thinks' that the protected group is at a disadvantage or is under-represented (section 159(1));

3) The action is with the aim of enabling or encouraging protected groups to overcome or minimise the disadvantage or participate in that activity (section 159(2)); 
4) The action is a proportionate means of achieving those aims (section 159(4)(c));

5) The employer does not have a policy of automatically treating persons in the protected group more favourably in connection with recruitment or promotion (section 159(4)(b)).

This has been described as the "tie-breaker" or "equal merit" provision. In the Government Equality Office's Quick Start Guide to using positive action in recruitment and promotion (Government Equalities Office, 2011), employers are advised to establish a set of criteria against which candidates will be assessed when applying for a job, including a candidate's overall ability, competence and professional experience, together with any relevant formal or academic qualifications, as well as any other qualities required to carry out the particular job. Where two candidates are "as qualified as" each other in respect of these criteria, and where the other criteria listed above are met, then an employer can take a candidate's protected characteristic into account as the "deciding factor" in determining who is to be offered the job.

The Quick Start Guide gives as example a recruitment exercise by a health and fitness club for a leisure facility manager. Following interview, the choice is between a woman who has recently completed a Leisure Management Foundation Degree course but has little practical experience and a man with no formal qualifications but several years of experience in working in leisure centres. The employer decides that both could do the job to the same standard but in different ways, as each would bring a different set of skills and experiences to the job. These provisions allow the employer to select the man because all of the other senior positions at the leisure complex were held by women (Government Equalities Office, 2011: 7).

These provisions therefore have the capacity, at least, to address underrepresentation and tackle disadvantage of any protected group. Nonetheless, a feature of the positive action provisions at European, and therefore at domestic, level is of course that such initiatives are voluntary, not mandatory. So, despite the Equality Act allowing employers to take positive action in general and in relation to recruitment and promotion in particular, and Government guidance encouraging its 
use, anecdotal evidence would suggest that there are relatively few employers who are prepared to embrace positive action initiatives, and even fewer who are prepared to use the tie-break provisions. Indications are then that the broadening of the positive action provisions has had little, if any, impact on the extent to which these initiatives are utilised, and therefore far less to have served the purpose of moving closer to achieving "full equality in practice" as envisaged by the European provisions.

\section{Implications of the public sector equality duty for positive action}

Discussing the requirements of the Public Sector Equality Duty (PSED), Fredman has argued that the duty to have due regard to the need to eliminate unlawful discrimination (set out in section 149(1)(a)), clearly points to the need for some preemptive action in cases where disparate impact has been clearly evidenced (2014: 354). This might be described as mandatory positive action to correct indirectly discriminatory practices, and would be categorised, in McCrudden's typology, as simply eradicating discrimination. Arguably, the PSED is, in another important respect, not entirely voluntary. We argue that similarities between the wording of the Public Sector Equality Duty (PSED) and the provisions of section 158 indicate that public sector employers are required to at least consider introducing positive action initiatives beyond eradicating discrimination. As a result of section 149 of the Equality Act 2010, the PSED now seeks to ensure that the promotion of equality is at the centre of the work of the public body. The general duty under section 149(1)(b) requires public authorities to exercise their functions with due regard to the need to advance equality of opportunity between persons who share a relevant characteristic and persons who do not share it.

In particular, this duty under section 149 involves having due regard to the need to take steps to meet the needs of those who share a protected characteristic that are different from the needs of those who do not share it, and encourage those who share a protected characteristic to participate in public life or in any other activity in which participation by such people is disproportionally low. The shift in approach in the legislation from 'promoting' to 'advancing' equality of opportunity would indeed suggest a more focused approach towards equality of outcome and the need for public sector bodies to be more proactive. Crucially, this may well also indicate that 
there is a requirement that public authorities consider alleviating disadvantage through advancement of equality of opportunity via the means provided by the positive action provisions.

\section{Outreach and positive action}

Whilst there is a lack of empirical research in relation to the use of positive action per se, it is not uncommon for employers to promote their use of lower level positive action (i.e. that permitted by section 158) as part of their overall diversity and inclusion policy. In 2008, the International Centre for Migration Policy Development produced a report based on a number of case studies of positive action measures deployed in the retail sector, manufacturing and the police, as well as measures developed via third-party positive action programmes (Strasser, Gachter \& Dzhengozova, 2008). In so doing, they identified five strategies that define positive action and considered this paradigm in relation to different countries and legal systems across the EU. These five strategies were consciously and firmly routed in a meaning of positive action that enables equality of opportunity, rather than outcome. In spite of some excellent recommendations arising from this work, limiting such exploration to relatively uncontroversial measures meant that it was much easier to promote the business case to employers as part of their recommendations.

This is true of many of the examples highlighted by the specialised and general media in this area. There are numerous examples of both private and public sector organisations that have demonstrated a commitment to utilising the positive action measures permitted by section 158. In particular:

- The development by HMRC (HM Revenue and Customs) of their 'embrace' programme, which supports and develops talented BAME (Black Asian and Minority Ethnic) employees in order to provide them with equal opportunity in recruitment and promotion (Foster, 2015a);

- The measures taken by the Barclays Group to engage with and recruit from the broadest graduate BAME talent pool possible (Foster, 2015b);

- Education charity Teach First's move to embed inclusive processes into its graduate recruitment practices and to attract more diverse talent onto its Leadership Development Programme (Foster, 2013a); 
- The Chartered Institute of Library and Information Professionals (CILIP) Encompass scheme which uses positive action to encourage those from BAME communities to develop and choose a career in library and information work (Foster, 2010a);

- The BBC setting up the Journalism Talent Pool to help increase the diversity of its workforce (Foster, 2010b);

- The Metropolitan Police Service introducing a positive action talent development programme to nurture BAME junior officers into senior leadership roles (Foster, 2013b).

The list goes on with numerous examples of good practice and innovative positive action measures being implemented by employers. As supported by Strasser et al (2008), all of those engaging in such measures would appear to recognise not only the social context within which they act, but also the business case for expanding their talent pool by using positive action. Yet, when looking for evidence of employers crossing the rubicon between 'outreach' and 'preferential treatment', the narrative dries up. Whilst there are some notable public sector exceptions (such as the Judicial Appointments Commission in the UK) where there was willingness to utilise 'preferential treatment' as advocated by section 159, most employers are silent on this matter. This has largely been borne out by the initial findings in the authors' study (see below).

\section{Bridging the gap}

As discussed, the theoretical debate around the consequences and implications of the Equality Act 2010 is well established. Development of the equality legislation in the UK has often been based on limited quantitative analysis, anecdotal evidence provided during consultation processes and wide-ranging theoretical exploration. In the words of Sir Bob Hepple (referring to Government deregulation of the labour market), such measures are 'based not on independent impartial research, but instead rely on anecdotal "evidence" and pressures from business organisations that have an interest in the results' (Hepple, 2013, p. 213). As we have seen, the UK response to the 2005 European Commission report on positive action made it clear that there is a lack of systematic research on the use of positive action by employers 
in the UK (McCrudden, 2005). Certainly, whilst there is some evidence of outreach mechanisms (as permitted by section 158 and as explored above), there is very little attitudinal research or collated evidence of the more controversial use of preferential treatment as expounded by section 159. There is, for example, too little evidence as to whether there is a difference of approach in relation to positive action between the private and public sector (although the most notable publicised tie-break use would appear to come from the public sector such as the JAC). There is, however, a small but emerging body of socio-legal study in relation to the equality legislation. A more recent example can be seen in the work commissioned by the Equality and Human Rights Commission in relation to caste discrimination (Dhanda et al, 2014).

Meaningful debate on the utility and development of positive action within the UK and beyond can only be achieved by assessing how the current legislative provisions are utilised in practice. As a non-mandatory provision, section 159 in particular can only really be analysed in light of how the law is being used by employers across the UK. Academic speculation (by those such as Johns et al, 2014), suggesting a 'muted' response to the tie-break provisions in recruitment and promotion), must be supported by empirical evidence enabling us to drill down into the underlying reasons. We can make vague assumptions as to why employers are not utilising the permissive positive action provisions. Is it a lack of awareness and/or understanding or is it something less tangible such as a wariness of the new paradigm of equality in the UK suggested by the application of section 159 (Noon, 2012)? Anecdote would suggest that it is the permissive nature of legislative positive action that discourages employers. Equally, the potential risks of introducing a viable positive action initiative, in light of possible legal challenge for 'reverse discrimination' from an unsuccessful candidate (for example in a tie-break situation), may be considered overly burdensome.

Positive action as a social phenomenon cannot be assessed without empirical exploration of the ground level attitudes of those responsible for recruitment and promotion practice in the UK. Whilst doctrinal analysis is sometimes sufficient to determine solutions to legal problems (Hutchinson, 2013), increasingly a socio-legal approach is vital to determining how the law applies in practice. Indeed, doctrinal wrestling in relation to positive action provides at most a limited analysis. At EU level we securely reference case law that points to a developing paradigm of positive 
action (see above). Undoubtedly comparative study provides an important evidential base for discussion. Nonetheless, the lack of meaningful data on the attitudes and use of British employers towards legislative provision in this area makes it impossible to assess our comparable position. In spite of the inherent difficulties in collecting relevant attitudinal empirical data in relation to the use of positive action, the smallscale research on which this paper is based attempts to formulate a methodological framework working towards an evidential base aimed at expanding dialogue in this area.

\section{The methodological framework}

The small-scoping study that is the main subject of this paper is the first stage of a broad based, multi-layered, mixed-method exploration of the awareness, use and perceptions of voluntary, public and private employers towards the existing positive action provisions of the Equality Act 2010 (more specifically the use of sections 158 and 159). The limited scoping study that has already been carried out uses the distribution of a basic questionnaire and it is upon an early analysis of this data that the remainder of this paper will focus. Using a process of purposive sampling targeting Human Resource professionals within large organizations and owners of small and medium-sized enterprises (SMEs) in England, Wales and Scotland, the questionnaire was disseminated to relevant networks. This has permitted initial qualitative and quantitative analysis of the relevant data. The aim of the scoping study was to: stimulate debate and provide some early outputs; inform future discussions about the shape, focus and priorities for the development of this work on a sectoral basis; and be of value to those undertaking research in this area in the future.

Analysis of the initial data from the scoping study will enable the drilling down of specific themes to allow for further broad scale questionnaires to be developed and used in targeted sectors such as Higher Education. The subsequent stage of the study will involve a series of individual semi-structured interviews and case studies with relevant representatives of a range of organisations, again focusing on specific sectors. Data will then be collated and triangulated in order to seek to respond to the core research questions, that is, the awareness, use and perceptions of organisations in relation to the positive action provisions of the Equality Act 2010. 
Overall, the methodology utilized in the scoping study has been successful in producing sufficient data to explore initial questions raised by this research.

\section{Data analysis}

Within this section, detail is provided regarding the key findings that have emerged hitherto from the scoping study.

As with any developmental study, work is in some respects ongoing - particularly with regard to the continued analysis of various aspects of the data. As such, these findings should be read in the context in which they are given - initial analyses of very complex data sets, intended to assist and inform the continued development of this research, rather than conclusions.

For ease of reference, the key findings of the research presented in this section will be discussed in with the light of the original focus of the research being the exploration of the perceptions of employers towards the positive action provisions of the Equality Act 2010 (in particular sections 158 and 159). The findings presented below are based on analyses of both qualitative and quantitative data gathered from a range of employers across the private and public sector.

At the time of writing, 24 organisations have participated in the study. Due to the small sample size, the researchers will make no attempt to generalize in relation to these early findings. Of these, 67 percent are from the public sector and 33 percent from the private sector. This predominance of public sector respondents may well be due to a greater engagement with equality issues as a result of the Public Sector Equality Duty and, as such, a greater willingness to engage in research in this area. There has been a varied distribution of responses across sectors including finance, business, health and social care, recruitment, charities and voluntary organisations, and education.

Perhaps due to the confines of the sampling and the necessity to utilize existing networks, the majority of responses (46 percent) have come from the Teaching and Education sector. Equally, the majority (83 percent) of those responding have more than 100 employees. As yet, 70 percent of respondents have been from England, 26 percent from Scotland, and four percent from Welsh organisations. 


\section{Awareness and cognizance}

As part of the scoping study, respondents were provided with objective background detail to sections 158 and 159 of the Equality Act 2010. They were then asked to respond to the question as to whether their organization had previously been aware of the provisions permitting positive action. Surprisingly, 25 percent of those surveyed were not aware of the positive action provisions. The majority (albeit involving small numbers) of those unaware of sections 158 and 159 were from the private sector respondents. This would support the view that the PSED has created greater awareness of positive action in public sector employers. Where the organization was aware of the positive action provisions, awareness of the positive action provisions had frequently come from third party stakeholders that appeared to have offered sector wide support to particular employers. For example, one large public sector company professed to having been made aware of the provisions via:

\section{Sector-wide briefings and information.}

Others frequently cited bodies such as the Equality Challenge Unit (the ECU) as being responsible for maintaining awareness and disseminating information regarding the positive action provisions:

Difficult to say precisely but shaped through the work of organisations such as the Equality Challenge Unit and HESA [Higher Education Statistics Agency], as well as expectations attached to public funding eg research funding.

These early findings support the recommendations made by the International Centre for Migration and Policy Development (Strasser et al, 2008) that reinforced the need to involve third party sectoral partners in relation to any positive action strategy.

Many of the respondents (and in particular those from the public sector) appeared to rely on dedicated equality and diversity teams to search for and locate information in relation to equality provisions, and this appeared to be very much a part of their overall Human Resource strategy.

Practice and usage

Whilst the majority of respondents had been previously aware of the positive action provisions, only a relatively small proportion of these (30 percent) stated that their 
organisation had previously used such provision. Thus, whilst the majority of organisations had an awareness and appeared to recognize the possibility of utilizing positive action, it was not something that had been rolled out in their particular organization. All of those responding positively to this question were from the education sector and were large public sector institutions. This would again support the view that those more readily engaged with positive action are those bodies who have a clear strategy in relation to the PSED. Those that had used positive action measures then provided examples of use. Almost all of those who provided such detail made reference to outreach programmes in their response, referring to both internal initiatives to promote diversity as well as external sectoral initiatives such as Athena Swan ${ }^{5}$ and the Disability Two Ticks Scheme ${ }^{6}$ :

Athena swan initiatives and leadership development training for early career, female academics. Two ticks initiative for disabled people in all areas.

We employ a lot of care workers and we are an employer of the Job Centre Two Ticks Scheme which means that candidates with a disability will automatically be interviewed.

Once again, the importance of third party initiatives aimed at promoting diversity and developed by social and sectoral partners was seen as a key driver in promoting the confidence and motivation to develop and roll out positive action measures.

Internal initiatives included training schemes geared towards women and minority ethnic staff, targeted mentoring, career development and leadership schemes and the development of specific networks for staff from protected groups:

leadership development training recruitment (GIS scheme for disabled people) awareness and comms activity [sic] establishment of staff affinity networks

5 The Equality Challenge Unit's Athena SWAN Charter was established in 2005 to encourage and recognise commitment to advancing the careers of women in science, technology, engineering, maths and medicine (STEMM) employment in higher education and research across the UK (Equality Challenge Unit, 2015)

6 The disability two ticks scheme in the UK is a recognition given by Jobcentre Plus to employers based in GB who have agreed to take action to meet five commitments regarding the employment, retention, training and career development of disabled employees (Gov.UK, 2015) 
BME leadership development programme for academic staff. Funding for dedicated support groups for BME, LGBT, Disabled staff.

Cryptically, only one respondent seemed to suggest a positive action measure that perhaps went beyond the outreach programmes suggested above but did not expand upon the basic statement:

This happens on a regular basis when employing new staff and promoting existing staff.

It would thus appear that, whilst the employers who do attempt to use positive action feel comfortable with the less controversial measures involving outreach, encouragement and training in order to create equality of opportunity, they are far less willing to consider moving into the realms of preferential treatment as permitted by section 159 .

\section{Inclination and alacrity}

When asked whether they would be willing to use the positive action provisions in the future, respondents returned a diverse range of responses. Whilst the majority (50 percent) of respondents were seemingly undecided in this regard, 30 percent were definite in responding that they could envisage utilizing the positive action provisions in the near future. Once again a reticence in relation to section 159 was evident. Concern was apparent regarding the potential legal consequences of applying a "reverse discrimination" approach to recruitment and promotion. The following comments from two separate respondents provide clear evidence of this:

Some aspects of the provision are liable for legal challenge.

If we identified areas of particular under representation and were $100 \%$ sure that in doing so we wouldn't actually be breaching equality legislation.

Equally, concern was expressed regarding the potential difficulties for employers around use of the 'tie-break' provision and perceptions of difficulty around determining what may amount to an "equally qualified comparator":

There is less hunger, amongst some organisations in private and public sector, for more concerted and direct activitiy through the use of the equally qualified comparator. This may be due to the vague nature of the current CoP [Code of Practice] that requires a test case before the remits of some of the more flexible provisions are clear. 
This concern regarding the boundaries and legal consequences of using section 159 was evident even in those respondents who were clearly well informed regarding the detail and coverage of the legal positive action provisions. This would support some of the anecdotal evidence that has become prevalent in this area.

Whilst a clear majority (75 percent) had been reticent about or could not envisage utilising the positive action provisions in their organisations in the near future, in contrast a significant majority (67 percent) expressed a personal view that the positive action provisions were necessary to alleviate disadvantage in the UK. This may suggest a discrepancy between personal subjective opinion, which may well be based on individual mores, and organisational perspectives which may necessarily involve a more objective risk-based approach towards positive action. Some of the qualitative subjective responses to this question appeared to have an in-depth understanding of the theoretical dialogue in this area and indeed were in support of preferential treatment under section 159:

I'd be in favour of a stronger provision such as 'threshold selection' (Mike Noon, 'The shackled runner' as I don't know that this provision is ever used).

I think it is crucial to get recruiters to think outside the box and to think of new ways of doing things.

Others appeared to transfer their professional reticence (which was more couched in concern regarding legal liability) into their personal theoretical philosophy:

I believe it's about the right person with the right skills for the right role, and in a fast paced commercial private sector environment that takes priority over diversity and inclusion.

One organisation linked use of positive action to increased diversity with improved productivity and, as such, focused on the business case argument:

A more proportionate representation in health and social care of various protected groups could result in better service provision.

Nevertheless, for many respondents, concerns were expressed regarding the business case for utilizing positive action within the workplace. In particular, a 
number of respondents appeared unconvinced regarding the impact on the productivity and efficacy of the organization:

We have identified areas of under-representation and could use positive action to address this. The benefits would show in our statistics but whether they would show in terms of actually being a more effective organisation, I don't know.

Others expressed concern that disadvantaged groups may perceive that any measures taken would impact on their credibility and position in the workplace:

Any action taken to tackle disadvantage is a positive one, but just because it is backed up by legislation, doesn't mean it will work. PLUS There is the worry that some may feel segregated.

Being able to use positive action would have benefits in terms of addressing disproportionality within the workforce, however, there is widespread concern (including from those who groups that are under-represented) that using positive action could undermine their credibility within the workforce.

\section{Implications and conclusions}

A number of themes can be determined from an early analysis of the ongoing scoping study carried out by the authors. Whilst it is not possible to generalise from this data due to the restricted sample size, it does appear that the initial findings do support the speculation as to the reasons why the positive action provisions (and in particular section 159) are not being effectively utilised in the UK. The link between the Public Sector Equality Duty and the positive action provisions was evident, to the extent that the study clearly demonstrated that those public sector bodies responding were aware of and on the whole had utilised some form of positive action measures in order to redress disadvantage in the workplace. Indeed, responses suggested that such organisations considered the use of positive action (as per section 158), where necessary to alleviate disadvantage, was part of their more general obligations under the Public Sector Equality Duty. Whilst there was a clear willingness and openness to use of outreach measures in order to redress disadvantage, there was evident wariness regarding a move towards preferential treatment as expounded by section 159. Even where individuals professed a subjective appreciation for 
more developed positive action, fear of creating segregation and stigmatisation for those benefiting from the 'tie-break' measure was clear in the responses provided. Supporting the 2008 International Centre for Migration and Policy Development report (Strasser et al, 2008), the data demonstrated that third party initiatives were vital in raising awareness and providing the know-how and confidence to utilise outreach positive action. In this regard, sector based kite marks such as Athena Swan and 'Two Ticks' were considered highly beneficial by those respondents from the educational public sector for example. Whilst respondents appeared to appreciate the business case for and utility of the positive action measures under section 158, there was far less enthusiasm for more direct preferential treatment, with many respondents raising serious concerns regarding this. These concerns often reflected a highly sensitive riskbased approach towards any action that could expose their organisation to the possibility of "reverse discrimination" legal liability. As such, it may be that the lack of clarity provided by section 159 (in particular) is failing to provide employers with the confidence they require. Arguably, it may be more appropriate to provide clearer legislative tools in this regard and more overtly remove the risk of "reverse discrimination".

These findings are a scratch on the surface of the empirical work that needs to be done in this area. At its best, positive action can be a quick and effective means of redressing the balance and addressing disadvantage. Nonetheless, whilst confusion and mistrust from employers around the permissive legal provisions (in particular in relation to preferential treatment) continues to exist, it is inevitable that such provisions will become the forgotten treasure of the equality legislation. As stated by one respondent in this scoping study:

Unfortunately positive action measures (certainly in the UK) have been piecemeal, not sustained or poorly focused in the past. They are also under researched and theorized.

Funding for wider research in this area is vital if we are to retain a useful purpose for positive action in the UK. An evidential foundation upon which to base any future dialogue around the development of legislative positive action in the UK is essential. In order to truly engage with the model of equality which is most 
appropriate for the UK (and beyond) and to cross the Rubicon of reticence from employers (which early findings as above would suggest), we need to understand how existing provisions are perceived and applied and, if necessary, determine a relevant business and social case on which to base future discussion. If we are still at the point of experimentation in relation to positive action in the EU and UK (Barmes, 2012), then theorising only progresses the discourse so far. In order to provide an appropriate 'starting line' for positive action to redress disadvantage (Noon, 2010), we must guarantee the starting blocks are constructed on solid footings. Those foundations must be constructed on the development of broad-based, ground-level empirical study.

\section{References}

Ayres I and Braithwaite J (1992) Responsive Regulation. New York: Oxford University Press.

Barmes L, (2009) Equality law and experimentation: the positive action challenge. Cambridge Law Journal 68(3): 623-654.

Connolly M (2011) Discrimination Law. London: Sweet \& Maxwell.

Davies C (2015) Positive Action under the Equality Act 2010 and the implications of the Public Sector Equality Duty for positive action in the UK. Emp.L.B..226: 24.

Davies C and Robison M (2015) Shifting the starting blocks: an exploration of the impact of positive action in the UK In: Beyond 2015: shaping the future of equality, human rights and social justice. London: Equality and Diversity Forum.

Dhanda M, Waughrey A, Keane D, Mosse D, Green R and Whittle S (2014) Caste in Britain: socio-legal review. Report for the Equality and Human Rights Commission. Manchester: Equality and Human Rights Commission.

Equality Act 2010: The Explanatory Notes. (c.15). London: HMSO.

Equality Challenge Unit (2014) ECU's Athena Swan Charter. Available at: www.ecu.ac.uk/equality-charters/athena-swan/ (accessed 8 September 2015). 
Equality and Human Rights Commission (2011) Employment statutory Code of Practice. London: HMSO

Foster C (2010a) The BBC: attracting black and minority ethnic journalists. Equal Opportunities Review 206.

Foster C (2010b) The CILIP: positive action scheme. Equal Opportunities Review 206.

Foster C (2013a) The metropolitan police service: developing BME leaders. Equal Opportunities Review 233.

Foster C (2013b) Teach First: embedding diversity into recruitment practices. Equal Opportunities Review 244.

Foster C (2015a) HM Revenue and Customs: developing BAME talent. Equal Opportunities Review 255.

Foster C (2015b) Barclays Group: recruiting BAME talent. Equal Opportunities Review 255.

Fredman S (2011) Discrimination Law. Oxford: Oxford University Press.

Fredman S (2014) Addressing disparate impact: indirect discrimination and the public sector duty. Industrial Law Journal 43(3): 349-363

Gov.UK (2015) Recruitment and disabled people. Available at: https://www.gov.uk/recruitment-disabled-people/encouraging-applications (accessed 8 September 2015).

Government Equalities Office (2011) Employers quick start guide to positive action in recruitment and promotion. Available at: https://www.gov.uk/government/publications/employers-quick-start-guide-topositive-action-in-recruitment-and-promotion (accessed 8 September 2015).

Hansard (2010) House of Lords Debate. (2009-10) 717, Col.691-694.

Hepple B (2011) Enforcing Equality Law: Two Steps Forward and Two Steps Backwards for Reflexive Regulation. Industrial Law Journal 40(4): 315-335.

Hepple B (2013) Back to the future: employment law under the coalition government. Industrial Law Journal 42(3): 203-223. 
Hepple B, Coussey M and Choudhury T (2000) Equality: A New Framework, Report of the Independent Review of the Enforcement of UK Anti-Discrimination Legislation. Oxford: Hart Publishing.

Hutchinson T (2013) Doctrinal research: researching the jury. In Watkins D and Burton M (eds) Research Methods in Law. London: Routledge.

Judicial Appointments Commission (2014) Equal merit provision: JAC Policy. London: Judicial Appointments Commission.

Johns N, MacBride-Stewart S, Powell, M and Green A (2014) When is positive action not positive action? Exploring the conceptual meaning and implications of the tie-break criterion in the UK Equality Act 2010. Equality, Diversity and Inclusion: An International Journal 33(1): 97-113.

Khaitan T (2015) A theory of Discrimination Law. Oxford: Oxford University Press.

Malleson K (2009) Diversity in the judiciary: the case for positive action. Journal of Law and Society 36(3): 376-402.

McCrudden C (1986) Rethinking positive action. Industrial Law Journal 15(1): 219-243.

McCrudden, C. (2005) Report on positive action measures. Report by the Commission's Network of legal experts on the application of Community law on equal treatment between women and men. European Commission, Directorate -General for Employment and Social Affairs, April 2005.

McCrudden C (2007) Equality legislation and reflexive regulation: a response to the Discrimination Law Review's Consultative Paper. Industrial Law Journal 36(3): 255-266.

Morgan B and Yeung K (2007) An Introduction to Law and Regulation: Text and Materials. Cambridge: Cambridge University Press.

Noon M (2010) The shackled runner: time to rethink positive discrimination? Work, Employment and Society 24(4): 728-739. 
Noon M (2012) Simply the best? The case of using threshold selection in hiring decisions. Human Resource Management Journal 22(1): 76-88.

O'Cinneide C (2009) Positive Action. In Lee Y and Goldschmidt J (eds) Taking Employment Discrimination Seriously: Chinese and European Perspectives. Leiden: Brill.

Robison M (2012) On track with diversity 2012. Liverpool: Institute of Employment Rights.

Robison M (2015) Positive action - your opportunity to advance equality. Available at: http://www.equalityhumanrights.com/about-us/devolvedauthorities/commission-scotland/legal-work-scotland/articles/positive-action\%E2\%80\%93-your-opportunity-advance-equality (accessed 8 September 2015).

Robison M and Burrows N (2006) Positive action for women in employment: time to align with Europe. Journal of Law and Society: 24-41.

Sabbagh D (2011) The rise of indirect affirmative action: converging strategies for promoting "diversity" in selective institutions of higher education in the United States and France. World Politics 63: 470-508.

Strasser E, August G and Dzhengozova M (2008) The benefits of positive action: thematic discussion paper on behalf of the European Union Agency for Fundamental Rights. Report by the International Centre for Migration and Policy Development. Vienna. March 2008. 